\title{
Reorganização das metas curriculares no ensino básico Português: 0 caso das Geociências
}

\author{
Jorge Bonito \\ Universidade de Évora. CIDTFF da \\ Universidade de Aveiro. Portugal. \\ jbonito@uevora.pt
}

\begin{abstract}
REORGANIZING CURRICULAR GOALS OF THE PORTUGUeSE BASIC EDUCATION: THE CASE OF GEOSCIENCES. In April 2012, the portuguese Ministry of Education and Science decided that development education should be guided by Curricular Goals, setting up, consistently, the knowledge and essential skills that students should acquire in different school years and content of each curriculum. Among others, was constituted a subgroup of reformulation of Curricular Goals for the discipline of Natural Sciences, with the objective of proposing targets, ensuring the necessary coordination between levels of education and between them and the content of programs. Curricular goals for the discipline of Natural Sciences 2nd and 3rd cycles of basic educationycle were defined, leaving out the 1st cycle. The contents of Geosciences are studied in $2 n d$ cycle (5th grade) and 3rd cycle (7th grade). This paper gives an overview of curriculum goals, content and academic time allocated to the teaching of geology in the basic education by sub-group, already approved by the Ministry of Education and Science.Citation: Bonito J. 2014. Reestruturação do ensino da Geociências na escolaridade básica e no ensino secundário português: o papel das metas curriculares. Terræ Didatica, 10(3):227-239. http://www.ige.unicamp.br/terraedidatica/.
\end{abstract}

KEY-WORDS: Natural sciences, curricular goals, curriculum, basic education.

RESUMO Em abril de 2012, o Ministério da Educação e Ciência português decidiu que o desenvolvimento do ensino deve ser orientado por Metas Curriculares, definindo-se, de forma consistente, os conhecimentos e as capacidades essenciais que os alunos devem adquirir, nos diferentes anos de escolaridade e nos conteúdos de cada programa curricular. Entre outros, foi constituído um subgrupo de trabalho de reformulação das Metas Curriculares para a disciplina de Ciências Naturais, com o objetivo de propor as metas, assegurando a necessária articulação entre os ciclos de ensino e entre estas e os conteúdos dos programas. Foram definidas metas curriculares para a disciplina de Ciências Naturais, do $2 .^{\circ}$ e $3 .^{\circ}$ ciclos do ensino básico, deixando de fora o $1 .^{\circ}$ ciclo. Os conteúdos de Geociências são estudados no $2 .^{\circ}$ ciclo (5. ${ }^{\circ}$ ano) e no $3 .^{\circ}$ ciclo (7. ano). Neste trabalho dá-se conta das metas curriculares, dos conteúdos e dos tempos letivos atribuídos ao ensino das Geociências no ensino básico pelo subgrupo de trabalho, já homologadas pelo Ministério da Educação e Ciência.

PALAVAS-CHAVE: Ciências naturais, metas curriculares, currículo, educação básica. 


\section{Notas sobre o currículo do ensino básico português}

A organização da educação escolar do sistema de ensino português, nos termos do n. ${ }^{\circ} 3$ do art. ${ }^{\circ} 4 .^{\circ}$ da Lei n. ${ }^{\circ} 46 / 86$, de 14 de outubro (Lei de Bases do Sistema Educativo), compreende os ensinos básico, secundário e superior. O ensino básico visa assegurar uma formação geral comum a todos os cidadãos, proporcionando a aquisição dos conhecimentos basilares que permitam o prosseguimento de estudos (n. ${ }^{\circ} 1$ do $^{\text {art. }}{ }^{\circ} 4 .^{\circ}$ do Decreto-Lei n. ${ }^{\circ}$ 139/2012, de 5 de julho). É universal, obrigatório e gratuito, ${ }^{1}$ com a duração de 9 anos. Compreende três ciclos sequenciais: o primeiro de quatro anos (6-10 anos de idade), o segundo de dois anos (10-12 anos de idade) e o terceiro de três anos (12-15 anos de idade). O 2. ${ }^{\circ}$ ciclo do ensino básico organiza-se por áreas interdisciplinares de formação básica. Em geral há um professor por área disciplinar. O $3 .^{\circ}$ ciclo do ensino básico organiza-se segundo um plano curricular unificado, desenvolvendo-se no regime de um professor por disciplina ou grupo de disciplinas.

O Decreto-Lei n. ${ }^{\circ}$ 139/2012, de 5 de julho aprovou as matrizes curriculares do ensino básico, que integram as áreas disciplinares e as disciplinas e a respetiva carga horária semanal mínima. A disciplina de Ciências Naturais integra a área disciplinar da Matemática e Ciências do 2. ${ }^{\circ}$ ciclo do ensino básico. As escolas têm liberdade, no âmbito da sua autonomia, de organizar os tempos letivos na unidade que considerem mais conveniente desde que respeitem as cargas horárias semanais. A carga horária semanal mínima, referente a tempo útil de aula, para cada ano de escolaridade nesta área científica, é de 350 minutos, num total de 700 minutos no final do ciclo. Porém, do total da carga horária, no mínimo, 250 minutos são atribuídos à disciplina de Matemática. Não podem ser aplicados apenas os mínimos, em simultâneo, em todas as disciplinas. O tempo a cumprir é realizado pelo somatório dos tempos alocados às diversas disciplinas, podendo ser feitos ajustes de compensação entre semanas. O tempo total a cumprir no $2 .^{\circ}$ ciclo do ensino básico é de 1350 minutos em cada ano de escolaridade. Quando da distribuição das cargas em tempos letivos sema-

1 A gratuidade do ensino básico abrange taxas e emolumentos relacionados com a matrícula, frequência e certificação, podendo ainda os alunos dispor gratuitamente do uso de livros e material escolar, bem como de transporte, alimentação e alojamento, quando necessários. nais resultar uma carga horária inferior ao tempo mínimo estabelecido, o tempo sobrante (diferença entre o somatório do número de minutos de cada disciplina e os 1350 minutos), é utilizando no reforço de atividades letivas da turma. Como referência e efeito exemplificativo, a carga horária semanal da área disciplinar da Matemática e Ciências organizada em períodos de 45 minutos corresponde a 9 tempos letivos para cada ano, dos quais 6 são obrigatoriamente destinados à Matemática e os restantes às Ciências Naturais.

A matriz curricular do $3 .^{\circ}$ ciclo do ensino básico segue os mesmos princípios de gestão do tempo. Inclui a área disciplinar de Ciências Físicas e Naturais, com duas disciplinas: Ciências Naturais e Físico-Química. A carga horária mínima em cada ano é de 270 minutos, num total de 810 minutos no $3 .^{\circ}$ ciclo do ensino básico. Como referência e efeito exemplificativo, a carga horária semanal desta área disciplinar organizada em períodos de 45 minutos corresponde a 6 tempos letivos para cada ano.

Em 2001, o então Ministério da Educação do Governo da República Portuguesa divulgou o Currículo Nacional do Ensino Básico - Competências Essenciais, passando a assumir, nesse ano letivo de 2001/2002 a referência central para o desenvolvimento do currículo do ensino básico, ${ }^{2}$ existindo competências específicas para cada área disciplinar. Porém, em 12 de dezembro de 2011, entendeu o Ministro da Educação e Ciência que o documento contém um conjunto de insuficiências que, embora debatidas no momento da sua implementação não foram ultrapassadas, e que, ao longo dos anos, se vieram a revelar questionáveis ou mesmo prejudiciais na orientação do ensino. ${ }^{3}$ Considera o despacho, na continuação, que "o documento não é suficientemente claro nas recomendações que insere. Muitas das ideias nele defendidas são demasiado ambíguas para possibilitar uma orientação clara da aprendizagem. A própria extensão do texto, as repetições de ideias e a mistura de orientações gerais com determinações dispersas tornaram-no num documento curricular pouco útil. Por outro lado, o documento insere uma série de recomendações pedagógicas que se vieram a revelar prejudiciais. Em primeiro lugar, erigindo a categoria de 'competências' como orientadora de todo o ensino, menorizou

2 URL: Http://www.dgidc.min-edu.pt/ensinobasico/index. php? $=$ directorio\&pid $=2$ (acesso: 19.01 .2014$)$.

3 Despacho n. ${ }^{0} 17$ 169/2011, de 12 de dezembro. 
o papel do conhecimento e da transmissão de conhecimentos, que é essencial a todo o ensino. Em segundo lugar, desprezou a importância da aquisição de informação, do desenvolvimento de automatismos e da memorização. Em terceiro lugar, substituiu objetivos claros, precisos e mensuráveis por objetivos aparentemente generosos, mas vagos e difíceis, quando não impossíveis de aferir. Dessa forma, dificultou a avaliação formativa e sumativa da aprendizagem. As competências não devem ser apresentadas como categoria que engloba todos os objetivos de aprendizagem, devendo estes ser claramente decompostos em conhecimentos e capacidades. Os conhecimentos e a sua aquisição têm valor em si, independentemente de serem mobilizados para a aplicação imediata".

Em síntese, o Ministro da Educação e Ciência considera que o Currículo Nacional do Ensino Básico - Competências Essenciais aderiu a versões extremas de algumas orientações pedagógicas datadas e não fundamentadas cientificamente, com o objetivo de impor essas visões como orientadoras oficiais de toda a aprendizagem, não devendo o currículo tornar-se um veículo para a imposição do experimentalismo pedagógico.

Nestes termos, o Ministro da Educação e Ciência determinou que o Currículo Nacional do Ensino Básico - Competências Essenciais deixaria de constituir-se como documento orientador do ensino básico e, consequentemente, deixava de ser referência para os documentos oficiais ministeriais, em particular os programas, as metas de aprendizagem, as provas e os exames nacionais. Os programas existentes e os seus auxiliares continuam a assumir-se como documentos orientadores do ensino, embora as referências que neles constem a conceitos do Currículo Nacional do Ensino Básico - Competências Essenciais deixam de ser interpretados à luz do que nele é exposto.

Ainda sobre o currículo nacional, o Ministério da Educação e Ciência (MEC) entende que este "deve definir os conhecimentos e as capacidades essenciais que todos os alunos devem adquirir e permitir aos professores decidir como ensinar de forma mais eficaz, gerindo o currículo e organizando da melhor forma a sua atividade letiva. Assim, deverá dar-se aos professores uma maior liberdade profissional sobre a forma como organizam e ensinam o currículo. Em paralelo, deverá ser feita uma avaliação mais rigorosa sobre o resultado do seu trabalho e do da escola, primordial- mente através da avaliação dos conhecimentos adquiridos pelos alunos. (...) O currículo deverá incidir sobre conteúdos temáticos, destacando o conhecimento essencial e a compreensão da realidade que permita aos alunos tomarem o seu lugar como membros instruídos da sociedade. É decisivo que, no futuro, não se desvie a atenção dos elementos essenciais, isto é, os conteúdos, e que estes se centrem nos aspetos fundamentais. Desta forma, o desenvolvimento do ensino em cada disciplina curricular será referenciado pelos objetivos curriculares e conteúdos de cada programa oficial e pelas metas de aprendizagem de cada disciplina" (Despacho n. ${ }^{\circ} 17$ 169/2011, de 12 de dezembro). No momento em que escrevemos este texto mantém-se a revogação do Currículo Nacional do Ensino Básico - Competências Essenciais, sem que exista um documento alternativo.

\section{Metas curriculares}

No tempo de Governação de Portugal do XVIII Governo Constitucional (2009-2011), a então Ministra da Educação Isabel Alçada definiu o projeto "Metas de Aprendizagem" inserido na Estratégia Global de Desenvolvimento do Currículo. Pretendia, com essa medida, "assegurar uma educação de qualidade e melhores resultados escolares nos diferentes níveis educativos" (Alçada 2012). As metas de aprendizagem concretizam-se "no estabelecimento de parâmetros que definem de forma precisa e escalonada as metas de aprendizagem para cada ciclo, o seu desenvolvimento e progressão por ano de escolaridade, para cada área de conteúdo, disciplina e área disciplinar. Correspondem a resultados da investigação nacional e internacional sobre padrões de eficácia no desenvolvimento curricular, que recomendam este tipo de abordagem" (Alçada 2012). Consistem na determinação "clara", para cada ano e cada disciplina, de quais são os conhecimentos e as competências que os alunos devem adquirir, um documento "não normativo", mas sim um "referencial". São destinadas, em primeiro lugar, aos professores, que podem utilizá-las para fazer a gestão curricular, preparar aulas, orientar e avaliar as aprendizagens dos alunos. Também se destinam aos pais e aos alunos, para que possam acompanhar e verificar as componentes essenciais das aprendizagens. ${ }^{4}$

4 A apresentação do projeto das metas de aprendizagem pode ser acom- 
A equipa coordenadora do Projeto Metas de Aprendizagem foi composta pelos seguintes elementos: Natércio Afonso (Coordenador), Alexandra Marques, Cecília Galvão, Isabel Lopes da Silva, Maria do Céu Roldão, Maria Helena Peralta e Teresa Leite. A primeira fase do projeto teve início em janeiro de 2010 e centrou-se na elaboração das metas de aprendizagem para a Educação Pré-Escolar e para o Ensino Básico. Este trabalho foi realizado por nove equipas de peritos coordenadas por docentes do ensino superior das respetivas áreas de especialização científica e didática. No caso das ciências, a elaboração das metas foi coordenada por Isabel Martins, da Universidade de Aveiro.

Em julho de 2010, o MEC tinha já duas propostas sobre as metas de aprendizagem. ${ }^{5}$ Perspetivava-se que no ano letivo 2010-2011 as metas de aprendizagem estivessem disponíveis em todas as escolas, sendo algumas acompanhadas por especialistas para se verificar se as metas eram realmente atingíveis e claras. A partir daí, haveria todo um processo de desenvolvimento, que também seria ajustado.

Com a perda das eleições do Partido Socialista (PS) em 5 de junho de 2011, da coligação entre o Partido Social Democrata (PSD) e o CDS - Partido Popular resultou o XIX Governo Constitucional que tomou posse em 21 de junho de 2011. O então nomeado Ministro da Educação e Ciência - Nuno Crato - determinou por Despacho n. ${ }^{\circ}$ 17 169/2011, de 12 de dezembro - que o Currículo Nacional do Ensino Básico - Competências Essenciais, como se disse, deixaria de se constituir como documento orientador do ensino básico. Em 2 de abril de 2012, juntamente com o Ministro de Estado e das Finanças - Vítor Gaspar - consideraram que se afigurava da maior importância a "a reformulação das metas de aprendizagem iniciadas em 2010 que mostraram algumas limitações quanto à função que poderiam ter na gestão do ensino. A forma como nelas foram compatibilizados os conteúdos programáticos com os objetivos do então "Currículo Nacional" criou obstáculos

panhada em http://metasdeaprendizagem.dge.mec.pt/sobre-0-projecto/ apresentacao/ (recuperado 2014, janeiro 19).

5 As metas de aprendizagem para a ex-disciplina de Ciências da Natureza (2. ${ }^{0}$ ciclo do ensino básico) podem, ainda, ser visualizadas em URL: http://metasdeaprendizagem.Dge.Mec.Pt/ensino-basico/metas-de-aprendizagem $/$ metas $/$ ? Area $=22 \&$ level $=4$ (acesso: 19.01.2014), Enquanto as metas da disciplina de ciências naturais ( $3 .^{\circ}$ ciclo do ensino básico) se encontram em url: http://metasdeaprendizagem.Dge.Mec. Pt/ensino-basico/metas-de-aprendizagem $/$ metas/?Area $=30 \& l$ evel $=6$ (acesso: 19.01.2014) tanto à autonomia pedagógica das escolas como à liberdade dos professores usarem a sua experiência e profissionalismo. Ao se confundirem metas de aprendizagem concretas com objetivos vagos e muito gerais, metas curriculares com métodos de ensino e metas cognitivas com atitudes, continuou-se a não se destacar devidamente os conhecimentos e capacidades a adquirir pelos alunos em cada disciplina" (Despacho n. ${ }^{\circ}$ 5306/2012, de 2 de abril).

Considera-se que o desenvolvimento do novo Currículo Nacional deve: conter padrões de rigor, criando coerência no que é ensinado nas escolas; permitir que todos os alunos tenham oportunidade de adquirir um conjunto de conhecimentos e de desenvolver capacidades fundamentais nas disciplinas essenciais; e garantir aos professores a liberdade de usar os seus conhecimentos, experiência e profissionalismo para ajudar os alunos a atingirem o seu melhor desempenho (Despacho n. ${ }^{\circ}$ 5306/2012, de 2 de abril). Nesse sentido, devem ser traçados padrões que considerem a formação integral dos alunos e a relevância do ensino para o mundo real, refletindo o conhecimento e as capacidades que as crianças necessitam de adquirir e de desenvolver para o seu sucesso no futuro.

No ensino de cada disciplina curricular deve dar-se prioridade aos conteúdos fundamentais, devendo ser referenciado pelos objetivos e pelos conteúdos de cada programa oficial. São, assim, definidas Metas Curriculares, nas quais são definidos, de forma consistente, os conhecimentos e as capacidades essenciais que os alunos devem adquirir, nos diferentes anos de escolaridade ou ciclos e nos conteúdos dos respetivos programas curriculares, sendo orientadoras de todo o ensino. A definição das Metas Curriculares, segundo o referido Despacho, organiza e facilita o ensino, fornecendo uma visão o mais objetiva possível daquilo que se pretende alcançar, permitindo que os professores se concentrem no que é essencial e ajuda a delinear as melhores estratégias de ensino. ${ }^{6}$

6 A revogação das Metas de Aprendizagem e a definição das Metas Curriculares não foi feita de modo inócuo. Na verdade, gerou-se um considerável debate e uma acesa contestação pelas partes opositoras à natureza das Metas Curriculares, particularmente pelos académicos da educação, que alternam as suas posições entre a consternação ao cancelamento do Currículo Nacional do Ensino Básico - Competências Essenciais e a recusa à definição de qualquer tipo de metas ou, de modo singular, às atuais Metas Curriculares (cf., e.g., Silva 2012, Galvão et al. 2013). Porém, outras vozes existem, e não são poucas, defensoras das Metas Curriculares, essencialmente pelo rigor e a exigência a que obrigam na lecionação das matérias e na definição clara e explícita do caminho da aprendizagem a seguir (cf., e.g., Cortez, 2013). 
Para cada disciplina e para cada etapa, devem, nestes termos, identificar-se, de forma clara: os conteúdos fundamentais que devem ser ensinados aos alunos; a ordenação sequencial ou hierárquica dos conteúdos ao longo das várias etapas de escolaridade; os conhecimentos e as capacidades a adquirir e a desenvolver pelos alunos; e os padrões/níveis esperados de desempenho dos alunos que permitam avaliar o cumprimento dos objetivos.

Para o efeito, foi criado na dependência direta do Ministro da Educação e Ciência, um grupo de trabalho de reformulação das Metas Curriculares, o qual tem por missão identificar o conjunto de conhecimentos e de capacidades essenciais que o aluno tem de adquirir e desenvolver, por ano de escolaridade ou ciclo, nas diferentes disciplinas dos ensinos básico e secundário. O grupo de trabalho tem a seguinte composição: Maria Isabel Festas (coordenadora), Maria Helena Damião e Filipe de Oliveira. Este grupo articula-se com o Ministro da Educação e Ciência através da adjunta do seu Gabinete - Maria Isabel Hormigo.

No âmbito deste grupo foram constituídos diversos subgrupos, um por cada disciplina do ensino básico. Os subgrupos tinham como missão propor Metas Curriculares para os diferentes anos de escolaridade ou ciclos, assegurando a necessária articulação entre os ciclos; e consagrar a articulação entre as metas e os conteúdos dos respetivos programas curriculares, apresentando os eventuais ajustamentos aos programas que se mostrem necessários. O subgrupo das Ciências Naturais foi constituído por Jorge Bonito (coordenador), da Universidade de Évora, e por docentes dos ensinos básico e secundário: Margarida Morgado, Marta Silva, Dulce Figueira, Marta Serrano, José Mesquita e Hugo Rebelo.

Os trabalhos do subgrupo das Ciências Naturais encetaram em janeiro de 2013, com o fito de definir as metas curriculares para esta disciplina, podendo implicar uma revisão parcial de alguns programas curriculares, devendo apenas alterar-se o que é estritamente necessário e justificável. A este subgrupo foi dada a oportunidade de se manterem contactos, solicitar informações e obter a colaboração de quaisquer entidades públicas ou privadas, relacionadas com as matérias a tratar. Reuniu-se, por isso, a colaboração de alguns consultores para a área das Geociências (Jorge Medina, da Universidade de Aveiro e Luís Lopes da Universidade de
Évora), para além da articulação com o $1 .{ }^{\circ}$ ciclo do ensino básico (Maria Boné do Agrupamento de Escolas de Monforte).

\section{0 ensino das Geociências no 2..$^{\circ}$ ciclo e no $3 .{ }^{\circ}$ ciclo do ensino básico - metas curriculares}

Considera-se "Domínio" uma área aglutinadora de conteúdos, a que corresponde uma unidade temática, podendo dividir-se em agrupamentos de menor inclusão, designados de "Subdomínios". A primeira tarefa do subgrupo das Ciências Naturais foi decompor os domínios em subdomínios e, estes, em rubricas (dimensões dos conteúdos) sequenciais e hierárquicas para cada ano de escolaridade $\left(5 .^{\circ}, 6 .^{\circ}, 7 .^{\circ}, 8^{\circ} \text { e } 9 .^{\circ} \text { anos de escolaridade }\right)^{7}$ - elenco de conteúdos. Procurou-se assegurar a coerência e a unidade entre os conteúdos, de forma que o aluno conseguisse inferir o esquema concetual de cada ano. Considerou-se que tal procedimento torna mais fácil que cada professor elabore uma lista de factos e subconceitos, de cuja inter-relação se produz o conceito e, a partir destes, princípios gerais. Este procedimento coloca em evidência a natureza da construção do pensamento científico e reforça a ideia de que a aprendizagem de conceitos e de princípios é hierarquicamente superior à dos factos, permitindo ao aluno alguma transferência do conhecimento para situações novas. O critério de identificação dos factos necessários para os conceitos selecionados dever orientar-se por esquemas concetuais elaborados, que revelam a ênfase e o caminho dados a cada subdomínio. A especificação dos conteúdos fez-se com base numa revisão da literatura científica mais atual, sendo oportunamente depurada pelos consultores. De seguida, procedeu-se à distribuição dos conteúdos pelo tempo mínimo disponível definido nas matrizes curriculares, considerando-se a experiência dos elementos docentes no ensino básico.

7 Algumas matérias ligadas às Geociências são objeto de aprendizagem no $1 .{ }^{\circ}$ ciclo do ensino básico. No "Estudo do Meio" os alunos estudam conteúdos relacionados com os elementos básicos do meio físico (o ar, a água, as rochas, 0 solo), os seres vivos que nele vivem, 0 clima, o relevo e os astros (Bloco 3 - À descoberta do ambiente natural). 0 Programa de Estudo do Meio encontra-se acessível em http://dge.mec.pt/metascurriculares/index.php? $s=$ directorio\&pid $=48$ (acesso: 20.01.2014). As metas curriculares para $01 .^{\circ}$ ciclo do ensino básico foram definidas apenas para Português e Matemática; por esse motivo, neste trabalho não se apresenta a componente da Geociências do Programa do $1 .{ }^{\circ}$ ciclo do ensino básico, aprovado em janeiro de 1990 (Despacho n. ${ }^{0}$ 139/ME/1990, de 16 de

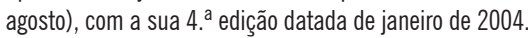


Reunindo-se a aprovação dos conteúdos, passou-se à construção das metas curriculares. Os objetivos gerais definidos representam aprendizagens complexas, apontando um caminho e a profundidade ao ensino e à aprendizagem. Comportam objetivos com menor grau de generalidade, com intencionalidade mais específica, designados neste contexto por descritores, organizados em cada ano de escolaridade, por domínios e subdomínios, segundo a seguinte estrutura:

\section{Domínio \\ Subdomínio \\ 1. Objetivo geral \\ 1.1. Descritor \\ 1.2. Descritor}

Os descritores indicam comportamentos observáveis que os alunos deverão revelar estando, em alguns casos, acompanhados de critérios de proficiência (em que medida?) e de condições (como?). Assim, elaborou-se uma sequência de objetivos e de descritores, no interior de cada subdomínio, correspondendo a uma progressão de ensino adequada. Pode optar-se, todavia, por alternativas coerentes que cumpram os mesmos objetivos e respetivos descritores. A construção dos descritores obedeceu ao princípio da correspondência entre os objetivos e os conteúdos do ensino. Espera-se, consequentemente, que exista também correspondência entre os conteúdos e os instrumentos de avaliação e entre estes e os objetivos.

A necessidade de provocar, estimular e desenvolver nos alunos aprendizagens de natureza distinta e de diverso nível de complexidade, levou a que se tivesse em consideração, na construção dos objetivos e dos respetivos descritores, a revisão da taxonomia de objetivos educacionais de Bloom (Anderson et al. 2001, Krathwohl 2002, Anderson e Losniak 2004). Partiu-se, por isso, do pressuposto que as operações cognitivas, expressas em comportamentos, num determinado nível requerem e incluem em si operações de níveis precedentes. As categorias taxonómicas dos objetivos não se excluem mutuamente. A complexidade das tarefas exige, por vezes, o recurso a diversas operações de níveis diferentes. Assim, por exemplo, quando se construiu um objetivo geral do domínio cognitivo (mental skills), ao nível da compreensão (understand), definiu-se descritores desse nível e do anterior (remember), precisamente porque não existe compreensão que não se apoie em recordação; porém, nenhum dos descritores ultrapassa o nível do objetivo. Evitou-se, deste modo, uma proliferação de descritores para cada nível, encontrando-se uma correspondência dos objetivos gerais aos respetivos conteúdos de ensino, sem repetição destes últimos. Optou-se por formar uma sequência de objetivos e de descritores, dentro de cada subdomínio, que corresponde a uma progressão de ensino adequada podendo, no entanto, optar-se por alternativas coerentes que cumpram os mesmos objetivos e respetivos descritores.

Os diferentes descritores estão redigidos de forma direta e objetiva, numa linguagem rigorosa, destinando-se ao professor, que deve selecionar as estratégias de ensino que lhe pareçam mais adequadas à respetiva concretização, incluindo uma adaptação da linguagem aos diferentes níveis de escolaridade. As metas agora estabelecidas significam que devem ser concretizadas num determinado ano de escolaridade. Na maioria dos casos, as operações cognitivas e skills manuais (capacidades cognitivas e psicomotoras) são retomadas em anos posteriores e/ou em outras disciplinas, com outra profundidade. Constituem, por isso, pré-requisitos para futuras aprendizagens. Considerando que estas são as metas essenciais a atingir, é importante não esquecer que, uma vez alcançadas, e havendo condições temporais para o efeito, é possível ir mais além, sendo o professor quem deve decidir por onde e como prosseguir.

As metas do ensino básico para a disciplina de Ciências Naturais (5. ${ }^{\circ}$ ao $8 .^{\circ}$ anos) foram homologadas pelo MEC em março de 2013 e as do $9 .^{\circ}$ ano em janeiro de 2014. As primeiras a serem homologadas são de aplicação obrigatória no ano letivo de 2014-2015 e as do 9. ${ }^{\circ}$ ano no ano letivo seguinte, sendo o referencial primordial da respetiva avaliação externa dos alunos (Despacho 15971/2012, de 7 de dezembro).

De seguida, dá-se conta, em sucessivos quadros sinóticos, das metas curriculares homologadas e de uma proposta de conteúdos e de tempos letivos associados, das matérias no âmbito das Geociências do $2 .^{\circ}$ e do $3 .^{\circ}$ ciclo do ensino básico. 


\section{$5 .^{0}$ ano de escolaridade $\left(2 .{ }^{\circ} \text { ciclo do ensino básico }\right)^{8}$}

Domínio: A água, o ar, as rochas e o solo - materiais terrestres 1665 min

Subdomínio: Importância das rochas e do solo na manutenção da vida 810 min

\begin{tabular}{|c|c|c|}
\hline Conteúdos & Metas & $\begin{array}{l}\text { Tempos } \\
\text { letivos }\end{array}$ \\
\hline $\begin{array}{l}\text { 1. Solo } \\
\text { 1.1. Fatores que condicionam a } \\
\text { formação e evolução de um solo } \\
\text { 1.2. Composição do solo - perfil } \\
\text { 1.3. Tipos de solo - porosidade e } \\
\text { permeabilidade } \\
\text { 1.4. Solo e agricultura } \\
\text { 1.5. Conservação do solo }\end{array}$ & $\begin{array}{l}\text { 1. Compreender que o solo é um material terrestre de } \\
\text { suporte de vida } \\
\text { 1.1. Apresentar a definição de solo. } \\
\text { 1.2. Indicar três funções do solo. } \\
\text { 1.3. Identificar os componentes e as propriedades do solo, } \\
\text { com base em atividades práticas laboratoriais. } \\
\text { 1.5. Descrever o papel dos agentes biológicos e dos } \\
\text { agentes atmosféricos na génese do solo. } \\
\text { 1.7. Relacionar a conservação do solo com a } \\
\text { sustentabilidade da agricultura. } \\
\text { 1.8. Associar alguns métodos e instrumentos usados na } \\
\text { agricultura ao avanço científico e tecnológico. }\end{array}$ & $360 \mathrm{~min}$ \\
\hline $\begin{array}{l}\text { 2. Rochas } \\
\text { 2.1. Conceitos de mineral e rocha - } \\
\text { propriedades básicas } \\
\text { 2.2. Principais grupos de rochas } \\
\text { 2.3. Minerais dos principais grupos } \\
\text { de rochas } \\
\text { 2.4. Distribuição geográfica das } \\
\text { rochas em Portugal } \\
\text { 2.5. Utilização atual das rochas e } \\
\text { minerais }\end{array}$ & $\begin{array}{l}\text { 2. Compreender a importância das rochas e dos minerais } \\
\text { 2.1. Apresentar uma definição de rocha e de mineral. } \\
\text { 2.2. Distinguir diferentes grupos de rochas, com base em } \\
\text { algumas propriedades, utilizando chaves dicotómicas } \\
\text { simples. } \\
\text { 2.3. Reconhecer a existência de minerais na constituição } \\
\text { das rochas, com base na observação de amostras de } \\
\text { mão. } \\
\text { 2.4. Referir aplicações das rochas e dos minerais em } \\
\text { diversas atividades humanas, com base numa atividade } \\
\text { prática de campo na região onde a escola se localiza. }\end{array}$ & $270 \min$ \\
\hline
\end{tabular}

Subdomínio: A importância da água para os seres vivos (450 min)

\begin{tabular}{|c|c|c|}
\hline Conteúdos & Metas & $\begin{array}{l}\text { Tempos } \\
\text { letivos }\end{array}$ \\
\hline $\begin{array}{l}\text { 2. Água } \\
\text { 2.1. A água e a vida } \\
\text { 2.1.1. Circulação da água na } \\
\text { natureza - ciclo hidrológico } \\
\text { 2.1.2. Distribuição da água no } \\
\text { planeta - reservatórios, fluxos e } \\
\text { águas subterrâneas } \\
\text { 2.1.3. Funções da água nos seres } \\
\text { vivos } \\
\text { 2.1.4. Água e saúde }\end{array}$ & $\begin{array}{l}\text { 4. Compreender a importância da água para os seres vivos } \\
\text { 4.1. Representar a distribuição da água no planeta } \\
\text { (reservatórios e fluxos), com recurso ao ciclo } \\
\text { hidrológico. } \\
\text { 4.2. Referir a disponibilidade de água doce (à superfície e } \\
\text { subterrânea) na Terra, a partir de informação sobre o } \\
\text { volume total de água existente. } \\
\text { 4.3. Identificar propriedades da água, com base em } \\
\text { atividades práticas laboratoriais. } \\
\text { 4.4. Apresentar exemplos que evidenciem a existência de } \\
\text { água em todos os seres vivos, através da consulta de } \\
\text { documentos diversificados. } \\
\text { 4.5. Descrever duas funções da água nos seres vivos. } \\
\text { 4.6. Explicar a importância da composição da água para a } \\
\text { saúde do ser humano, a partir da leitura de rotulagem. } \\
\text { 4.7. Referir o papel do flúor na saúde oral. }\end{array}$ & $225 \mathrm{~min}$ \\
\hline
\end{tabular}

8 A numeração das metas não segue a ordem original, uma vez que na disciplina se incluem outros conteúdos exteriores à área das Geolociências. As metas curriculares e o Programa de Ciências Naturais do $2 .{ }^{\circ}$ ciclo do ensino básico encontram-se disponíveis em URL: http://dge.mec.pt/metascurriculares/index. php? $=$ directorio\&pid $=22$ (acesso: 19.01 .2014$)$. 
2.2. Agua e atividade humana

2.2.1. Qualidade da água - potável e imprópria para consumo

2.2.2. Consumo de água

- A situação em Portugal

- Medidas de poupança

2.2.3. Poluição da água contaminação biológica, química e física

2.2.4. Tratamento de água

- ETA: decantação, filtração, fervura, desinfeção química e destilação

- ETAR: tratamento de águas residuais
5. Compreender a importância da qualidade da água para a atividade humana

5.1. Classificar os tipos de água própria para consumo (água potável e água mineral) e os tipos de água imprópria para consumo (água salobra e água inquinada).

5.2. Descrever a evolução do consumo de água em Portugal, com base em informação expressa em gráficos ou tabelas.

5.3. Propor medidas que visem garantir a sustentabilidade da água própria para consumo.

5.4. Indicar três fontes de poluição e de contaminação da água.

5.5. Explicar as consequências da poluição e da contaminação da água

5.6. Distinguir a função da Estação de Tratamento de Águas da função da Estação de Tratamento de Águas Residuais.

\section{7. ${ }^{0}$ ano de escolaridade (3. ${ }^{0}$ ciclo do ensino básico $)^{9}$}

Domínio: Terra em transformação (4455min)

Subdomínio: Dinâmica externa da Terra (675 min)

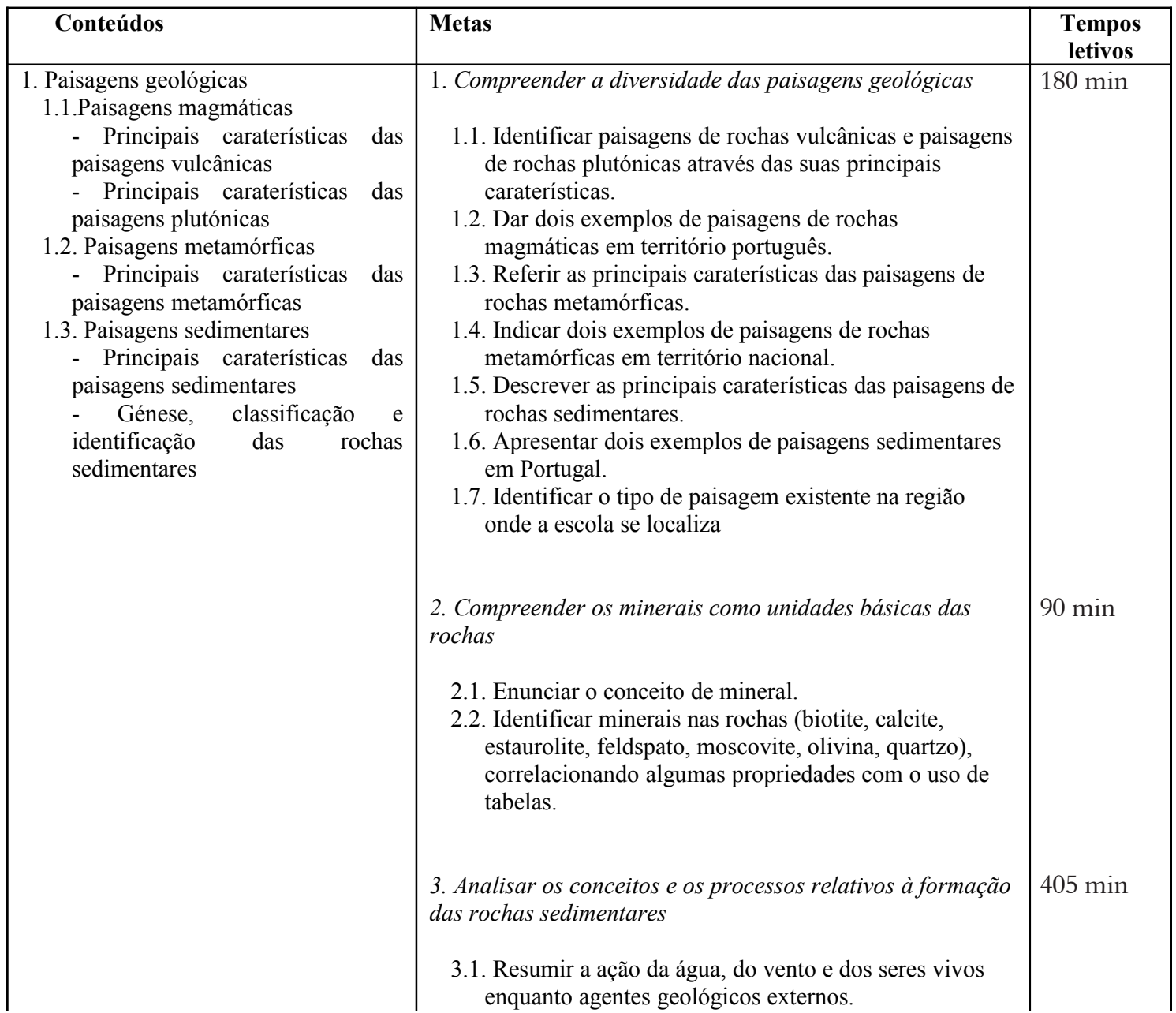

9 As metas curriculares e o Programa de Ciências Naturais do $3 .{ }^{\circ}$ ciclo do ensino básico encontram-se disponíveis em URL: http://dge.mec.pt/metascurriculares/ index.php?s= directorio\&pid = 22 (acesso: 19.01.2014) 


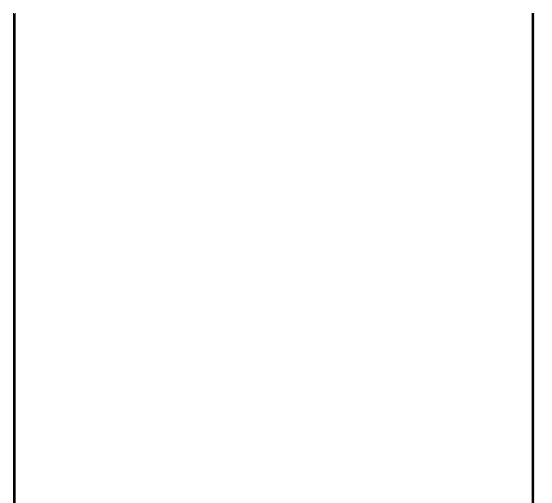

3.2. Prever o tipo de deslocação e de deposição de materiais ao longo de um curso de água, com base numa atividade prática laboratorial.

3.3. Explicar as fases de formação da maior parte das rochas sedimentares.

3.4. Propor uma classificação de rochas sedimentares, com base numa atividade prática.

3.5. Identificar os principais tipos de rochas detríticas (arenito, argilito, conglomerado, marga), quimiogénicas (calcário, gesso, sal-gema) e biogénicas (carvões, calcários), com base em atividades práticas.

3.6. Associar algumas caraterísticas das areias a diferentes tipos de ambientes, com base numa atividade prática laboratorial.

Subdomínio: Estrutura e dinâmica interna da Terra (540 min)

\begin{tabular}{|l|}
\hline Conteúdos \\
\hline 2. Deriva dos continentes e tectónica de \\
placas \\
2.1. Teoria da deriva continental \\
2.2. Teoria da expansão dos fundos \\
oceânicos
\end{tabular}

2.3. Teoria da tectónica de placas

3. Deformação das rochas 3.1. O comportamento das rochas quando sujeitas a tensões 3.2. Falhas e fraturas 3.3. Dobras e cavalgamentos
4. Compreender os fundamentos da estrutura e da dinâmica da Terra

4.1. Apresentar argumentos que apoiaram e fragilizaram a Teoria da Deriva Continental.

4.2. Reconhecer o contributo da ciência, da tecnologia e da sociedade para o conhecimento da expansão dos fundos oceânicos.

4.3. Esquematizar a morfologia dos fundos oceânicos.

4.4. Explicar as evidências clássicas (oceânicas e continentais) que fundamentam a Teoria da Tectónica de Placas.

4.5. Relacionar a expansão e a destruição contínuas dos fundos oceânicos com a constância do volume da Terra.

4.6. Resolver um exercício que relacione a distância ao eixo da dorsal atlântica com a idade e o paleomagnetismo das rochas do respetivo fundo oceânico.

4.7. Identificar os contributos de alguns cientistas associados à Teoria da Deriva Continental e à Teoria da Tectónica de Placas.

4.8. Caraterizar placa tectónica e os diferentes tipos de limites existentes.

4.9. Inferir a importância das correntes de convecção como "motor" da mobilidade das placas tectónicas.

\section{Aplicar conceitos relativos à deformação das rochas}

5.1. Distinguir comportamento frágil de comportamento dúctil, em materiais diversos, com base numa atividade prática laboratorial.

5.2. Explicar a formação de dobras e de falhas, com base numa atividade prática laboratorial.

5.3. Relacionar a movimentação observada numa falha com o tipo de forças aplicadas que the deram origem.

5.4. Identificar, em esquema e imagem, as deformações observadas nas rochas existentes nas paisagens.

5.5. Relacionar a deformação das rochas com a formação de cadeias montanhosas 
Subdomínio: Consequências da dinâmica interna da Terra (1575 min)

\begin{tabular}{|c|c|c|}
\hline Conteúdos & Metas & $\begin{array}{l}\text { Tempos } \\
\text { letivos }\end{array}$ \\
\hline $\begin{array}{l}\text { 4. Magmatismo e rochas magmáticas } \\
\text { 4.1. Vulcanismo e atividade } \\
\text { vulcânica } \\
\text { - Vulcões e tipos de atividade } \\
\text { vulcânica - principais tipos de } \\
\text { magmas } \\
\text { - Manifestações de vulcanismo } \\
\text { secundário } \\
\text { - Distribuição dos vulcões na } \\
\text { Terra e tectónica de placas } \\
\text { - Riscos vulcânicos: previsão e } \\
\text { proteção dos bens e das pessoas } \\
\text { 4.2. Génese, classificação e } \\
\text { identificação das rochas magmáticas } \\
\text { (vulcânicas e plutónicas) - granito, } \\
\text { riólito, gabro, basalto }\end{array}$ & $\begin{array}{l}\text { 6. Compreender a atividade vulcânica como uma } \\
\text { manifestação da dinâmica interna da Terra } \\
\text { 6.1. Esquematizar a estrutura de um aparelho vulcânico. } \\
\text { 6.2. Distinguir diferentes materiais expelidos pelos } \\
\text { vulcões, com base em amostras de mão. } \\
\text { 6.3. Estabelecer uma relação entre os diferentes tipos de } \\
\text { magmas e os diversos tipos de atividade vulcânica, } \\
\text { através de uma atividade prática. } \\
\text { 6.4. Exemplificar manifestações de vulcanismo } \\
\text { secundário. } \\
\text { 6.5. Explicar os benefícios do vulcanismo (principal e } \\
\text { secundário) para as populações. } \\
\text { 6.6. Referir medidas de prevenção e de proteção de bens e } \\
\text { de pessoas do risco vulcânico. } \\
\text { 6.7. Inferir a importância da ciência e da tecnologia na } \\
\text { previsão de erupções vulcânicas. } \\
\text { 6.8. Reconhecer as manifestações vulcânicas como } \\
\text { consequência da dinâmica interna da Terra. } \\
\text { (gabro e granito) e vulcânicas (basalto e riólito), com } \\
\text { base em amostras de mão. } \\
\text { 7. Interpretar a formação das rochas magmáticas } \\
\text { identificação macroscópica dos seus minerais } \\
\text { constituintes. }\end{array}$ & $405 \mathrm{~min}$ \\
\hline $\begin{array}{l}\text { 5. Génese das rochas metamórficas } \\
\text { 5.1. Fatores, intensidade e tipos de } \\
\text { metamorfismo } \\
\text { 5.2. Metamorfismo e dinâmica } \\
\text { interna da Terra } \\
5.3 \text { Classificação e identificação de } \\
\text { rochas metamórficas }\end{array}$ & $\begin{array}{l}\text { 8. Compreender o metamorfismo como uma consequência } \\
\text { da dinâmica interna da Terra } \\
\text { 8.1. Explicar o conceito de metamorfismo, associado à } \\
\text { dinâmica interna da Terra. } \\
\text { 8.2. Referir os principais fatores que estão na origem da } \\
\text { formação das rochas metamórficas. } \\
\text { 8.3. Distinguir metamorfismo de contacto de } \\
\text { metamorfismo regional, com base na interpretação de } \\
\text { imagens ou de gráficos. } \\
\text { 8.4. Identificar diferentes tipos de rochas metamórficas } \\
\text { (xistos e outras rochas com textura foliada e/ou } \\
\text { bandada bem definida; mármores; quartzitos, que } \\
\text { apresentem textura granoblástica), com recurso a uma } \\
\text { atividade prática. } \\
\text { 8.5. Relacionar o tipo de estrutura que a rocha apresenta } \\
\text { com o tipo de metamorfismo que lhe deu origem, em } \\
\text { amostras de mão. }\end{array}$ & $405 \mathrm{~min}$ \\
\hline
\end{tabular}


6. Ciclo das Rochas

7. Principais formações litológicas em Portugal

\section{Atividade sísmica}

8.1. Origem e registo das ondas sísmicas

8.2. Distribuição dos sismos na Terra e tectónica de placas

8.3. Riscos sísmicos - previsão e proteção dos bens e das pessoas
9. Conhecer o ciclo das rochas

9.1. Descrever o ciclo das rochas.

9.2. Enunciar os processos geológicos envolvidos no ciclo das rochas.

10. Compreender que as formações litológicas em Portugal devem ser exploradas de forma sustentada

10.1. Identificar os diferentes grupos de rochas existentes em Portugal, utilizando cartas geológicas.

10.2.Referir aplicações das rochas na sociedade.

10.3.Reconhecer as rochas utilizadas em algumas construções, na região onde a escola se localiza.

10.4.Defender que a exploração dos recursos litológicos deve ser feita de forma sustentável.

11. Compreender a atividade sísmica como uma

consequência da dinâmica interna da Terra

11.1.Explicar a formação de um sismo, associado à dinâmica interna da Terra.

11.2.Associar a vibração das rochas ao registo das ondas sísmicas.

11.3.Distinguir a Escala de Richter da Escala Macrossísmica Europeia.

11.4.Explicitar a intensidade sísmica, com base em documentos de sismos ocorridos.

11.5. Interpretar cartas de isossistas, em contexto nacional.

11.6. Identificar o risco sísmico de Portugal e da região onde a escola se localiza.

11.7.Caraterizar alguns episódios sísmicos da história do território nacional, com base em pesquisa orientada.

11.8. Indicar os riscos associados à ocorrência de um sismo.

11.9. Descrever medidas de proteção de bens e de pessoas, antes, durante e após a ocorrência de um sismo.

11.10. Reconhecer a importância da ciência e da tecnologia na previsão sísmica.

11.11. Relacionar a distribuição dos sismos e dos vulcões na Terra com os diferentes limites de placas tectónicas.
$90 \mathrm{~min}$

$630 \mathrm{~min}$

Subdomínio: Estrutura interna da Terra (450 min)

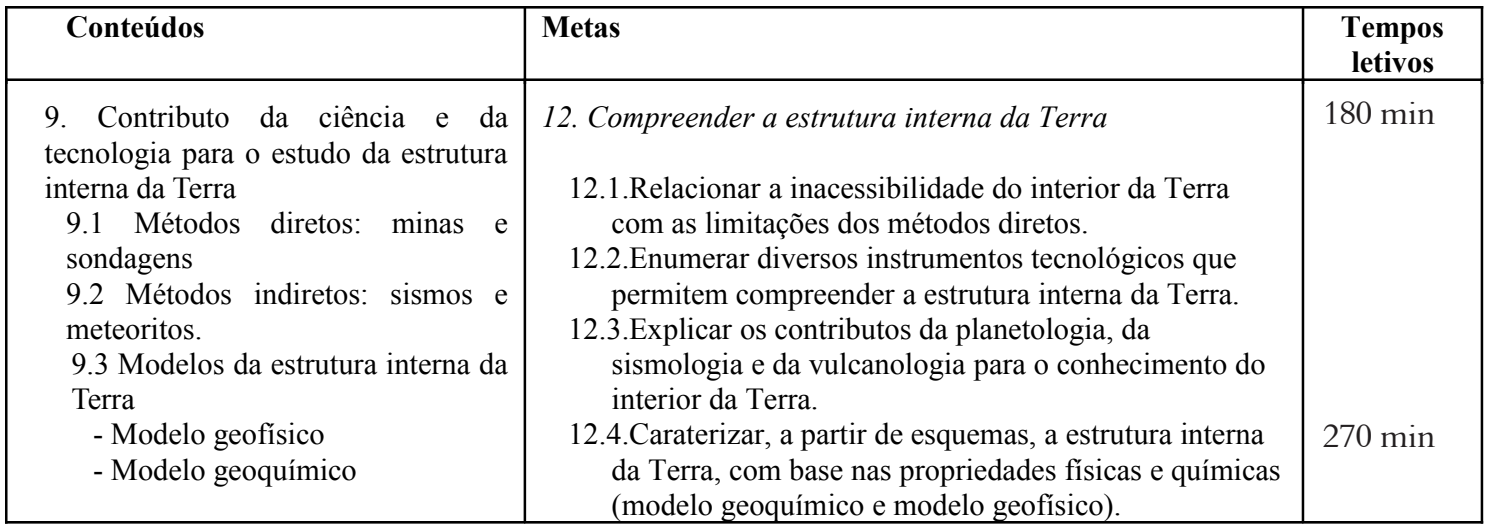


Subdomínio: A Terra conta a sua história (945 min)

\begin{tabular}{|c|c|c|}
\hline Conteúdos & Metas & $\begin{array}{c}\text { Tempos } \\
\text { letivos }\end{array}$ \\
\hline $\begin{array}{l}\text { 10. Grandes etapas na história da Terra } \\
\text { 10.1. Tempo histórico e tempo } \\
\text { geológico } \\
\text { 10.2. Tempos em geologia - relativo } \\
\text { e absoluto } \\
\text { 10.3. Escala do tempo geológico - } \\
\text { tabela estratigráfica } \\
\text { 10.3. Tempo geológico e } \\
\text { sustentabilidade da vida }\end{array}$ & $\begin{array}{l}\text { 13. Compreender a importância dos fósseis para a } \\
\text { reconstituição da história da Terra } \\
\text { 13.1.Definir paleontologia. } \\
\text { 13.2. Apresentar uma definição de fóssil. } \\
\text { 13.3. Explicar os diversos processos de fossilização, } \\
\text { recorrendo a atividades práticas. } \\
\text { 13.4.Relacionar a formação de fósseis com as condições } \\
\text { físicas, químicas e biológicas dos respetivos } \\
\text { ambientes. } \\
\text { 13.5. Ordenar acontecimentos relativos a processos de } \\
\text { fossilização, de acordo com a sequência em que estes } \\
\text { ocorreram na Natureza. } \\
\text { 13.6.Caraterizar os grandes grupos de fósseis, com base } \\
\text { em imagens e em amostras de mão. } \\
\text { 13.7.Explicar o contributo do estudo dos fósseis para a } \\
\text { reconstituição da história da vida na Terra. }\end{array}$ & $495 \mathrm{~min}$ \\
\hline $\begin{array}{l}\text { 11. Os fósseis e a sua importância para } \\
\text { a reconstituição da história da Terra } \\
\text { 11.1. Fósseis e paleontologia } \\
\text { 11.2. Processos } \\
\text { 11.3. Interpretação } \\
\text { 11.4. Flora e fauna como memória }\end{array}$ & $\begin{array}{l}\text { 14. Compreender as grandes etapas da história da Terra } \\
\text { 14.1.Sistematizar informação, em formatos diversos, sobre } \\
\text { o conceito de tempo. } \\
\text { 14.2.Distinguir tempo histórico de tempo geológico, com } \\
\text { base em documentos diversificados. } \\
\text { 14.3.Explicar o conceito de datação relativa, com base nos } \\
\text { princípios do raciocínio geológico e com recurso a } \\
\text { uma atividade prática laboratorial. } \\
\text { 14.4.Distinguir datação relativa de datação radiométrica. } \\
\text { 14.5. Localizar as Eras geológicas numa Tabela } \\
\text { Cronoestratigráfica. } \\
\text { 14.6. Localizar o aparecimento e a extinção dos principais } \\
\text { grupos de animais e de plantas na Tabela } \\
\text { Cronoestratigráfica. } \\
\text { 14.7. Inferir as consequências das mudanças cíclicas dos } \\
\text { subsistemas terrestres (atmosfera, biosfera, geosfera, } \\
\text { hidrosfera) ao longo da história da Terra, com base em } \\
\text { documentos diversificados. } \\
\text { 14.8.Caraterizar ambientes geológicos passados, através } \\
\text { de uma atividade prática de campo. }\end{array}$ & $450 \mathrm{~min}$ \\
\hline
\end{tabular}

Subdomínio: Ciência geológica e sustentabilidade da vida na Terra (270 min)

\begin{tabular}{|c|c|c|}
\hline Conteúdos & Metas & $\begin{array}{c}\text { Tempos } \\
\text { letivos }\end{array}$ \\
\hline $\begin{array}{l}\text { 12. Conhecimento geológico e } \\
\text { sustentabilidade da vida na Terra } \\
\text { 12.1. As intervenções do ser humano } \\
\text { nos processos geológicos e } \\
\text { biológicos } \\
\text { 12.2. Impacte sobre o sistema } \\
\text { geológico externo suas } \\
\text { consequências na sustentabilidade da } \\
\text { vida } \\
\text { 12.3. Impacte do desenvolvimento } \\
\text { científico e tecnológico na sociedade } \\
\text { 12.4. Respostas aos problemas de } \\
\text { geologia ambiental }\end{array}$ & $\begin{array}{l}\text { 15. Compreender o contributo do conhecimento geológico } \\
\text { para a sustentabilidade da vida na Terra } \\
\text { 15.1.Associar as intervenções do ser humano aos impactes } \\
\text { nos processos geológicos (atmosfera, hidrosfera e litosfera). } \\
\text { 15.2. Relacionar o ambiente geológico com a saúde e a } \\
\text { ocorrência de doenças nas pessoas, nos animais e nas plantas } \\
\text { que vivem nesse mesmo ambiente. } \\
\text { 15.3.Extrapolar o impacte do crescimento populacional no } \\
\text { consumo de recursos, no ambiente e na sustentabilidade da } \\
\text { vida na Terra. } \\
\text { 15.4.Referir três tipos de respostas (tecnológicas, } \\
\text { socioeconómicas e educativas) a problemas de geologia } \\
\text { ambiental. } \\
\text { 15.5.Explicar o modo como as relações entre a geologia, a } \\
\text { tecnologia e a sociedade podem contribuir para a formação } \\
\text { de uma cultura de sustentabilidade da vida na Terra. }\end{array}$ & $270 \mathrm{~min}$ \\
\hline
\end{tabular}


Em síntese, podemos constatar, desde modo, que as Geociências no ensino básico são estudadas no $1 .^{\circ}$ ciclo (água, rochas, o solo, relevo, astros), no $2 .^{\circ}$ ciclo (5. ${ }^{\circ}$ ano $)$ - solo, rochas, água - e no 7. ${ }^{\circ}$ ano $\left(3 .^{\circ}\right.$ ciclo) (dinâmicas externa da Terra; estrutura, dinâmica interna da Terra e suas consequências; história da Terra; ciência geológica e a sustentabilidade da vida na Terra), estando definidas metas curriculares apenas para o $2 .^{\circ}$ e $3 .^{\circ}$ ciclos do ensino básico.

\section{Referências bibliográficas}

Alçada I. 2012. Metas de aprendizagem. URL: http:// metasdeaprendizagem.dge.mec.pt/. Acesso 19.01.2014.

Anderson L.W., Krathwohl D.R., Airasian P.W., Cruikshank K.A., Mayer R.E., Pintrich P.R., Raths J., Wittrock M.C. eds. 2001. A taxonomy of learning, teaching, and assessing: A revision of Bloom's Taxonomy of Educational Objectives. Boston: Allyn \& Bacon.

Anderson L.W., Losniak L. O. eds. 2004. Bloom's Taxonomy. A forty-year retrospective. Chicago: University of Chicago Press.

Bonito J., Morgado M., Silva M., Figueira D., Serrano M., Mesquita J., Rebelo H. 2012. Metas curriculares. Ensino Básico. Ciências Naturais. 5. ${ }^{\circ}, 6 .^{\circ}, 7 .^{\circ}$ e 8..$^{\circ}$ anos. Lisboa: Direção-Geral da Educação. URL: http://dge.mec.pt/metascurriculares/index. php? $=$ directorio\&pid $=22$. Acesso 19.01.2014.

Cortez A.C. 2013, 27 de novembro. Verdades sobre o ensino do português: metas curriculares e não só. Público. URL: http://www.publico.pt/sociedade/ noticia/verdades-sobre-o-ensino-do-portuguesmetas-curriculares-e-nao-so-1614035. Acesso 22.01.2014

Galvão C. et al. 2013. Apreciação Crítica das Propostas de Metas Curriculares de Ciências Naturais (em Discussão Pública até ao dia 25 de março de 2013). URL: http://blogs.ua.pt/ctspc/wp-content/uploads/2013/04/An\%C3\%A1lise-de-metas-curriculares-de-Ci\%C3\%AAncias-Naturais-24MarFormatado.pdf. Acesso 22.01.2014.

Krathwohl D.R. 2002. A Revision of Bloom's Taxonomy: An Overview. Theory into practice, 41(4), 212-264. URL: http://www.unco.edu/cetl/sir/stating_outcome/documents/Krathwohl.pdf. Acesso 20.01.2014.
Silva J.C. 2012. Metas Curriculares-Ensino Básico-Matemática Parecer. URL: http://www. apm.pt/files/205600_Metas_Curriculares-parecerJCS_5192c70042133.pdf. Acesso 20.01.2014.

\section{Legislação}

Portugal. Lei n. ${ }^{\circ}$ 46/86, de 14 de outubro. Lei de Bases do Sistema Educativo. Diário da República, 1. ${ }^{a}$ série, 237, 14 de outubro. URL: http://www. dges.mctes.pt/NR/rdonlyres/2A5E978A-0D634D4E-9812-46C28BA831BB/1126/L4686.pdf. Acesso 19.01.2014.

Portugal. Decreto-Lei n. ${ }^{0}$ 139/2012, de 5 de julho. Diário da República, 1. ${ }^{a}$ série, 129, 5 de julho. URL: http:// dre.pt/pdf1sdip/2012/07/12900/0347603491.pdf. Acesso 19.01.2014.

Portugal. Despacho n. ${ }^{\circ}$ 15971/2012, de 7 de dezembro. Diário da República, 2. ${ }^{a}$ série, 242, 14 de dezembro. URL: http://www.gave.min-edu.pt/np3c ontent $/$ ?newsId $=31 \&$ fileName $=$ Despacho_ 1597 1_2012_14dez.pdf. Acesso 20.01.2014.

Portugal. Despacho n. ${ }^{\circ}$ 5306/2012, de 2 de abril. Diário

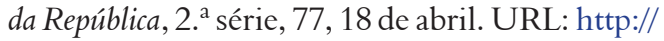
dre.pt/pdf2sdip/2012/04/077000000/1395213953. pdf. Acesso 19.01.2014.

Portugal. Despacho n. ${ }^{\circ}$ 17169/2011, de 12 de de-

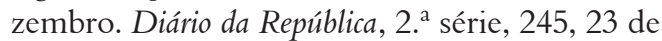
dezembro. URL: http://www.gave.min-edu.pt/ np3content $/$ ?newsId $=31 \&$ fileName $=$ Despacho n__171692011_CNEB.pdf. Acesso 19.01.2014.

- Portugal. Despacho n. ${ }^{\circ}$ 139/ME/1990,16 de agosto. Diário da República, 2. ${ }^{\mathrm{a}}$ série, 202, 1 de setembro.pdf2sdip/2012/04/077000000/1395213953. pdf. acesso 19.01.2014.

Portugal. Despacho n. ${ }^{\circ}$ 17169/2011, de 12 de dezembro. Diário da República, 2. ${ }^{a}$ série, 245, 23 de dezembro. URL: http://www.gave.min-edu.pt/ np3content $/$ ?newsId $=31 \&$ fileName $=$ Despacho n__171692011_CNEB.pdf. Acesso 19.01.2014.

- Portugal. Despacho n. ${ }^{\circ}$ 139/ME/1990, 16 de agosto. Diário da República, 2. ${ }^{a}$ série, 202, 1 de setembro. 